\title{
Is multidisciplinary learning valuable to build a breast cancer specialist career? The perspective of the first 2 cohorts of the ESO-ULM Certificate of Competence in Breast Cancer (CCB)
}

Meani Francesco ${ }^{1,26 *}$, Wandschneider Wiebke ${ }^{1,26}$, Abdelrahman Fadwa ${ }^{2}$, Ali Nasir ${ }^{3}$, Angelopoulos Miltiadis ${ }^{4}$, Benbrahim Zineb ${ }^{5}$, Carrión Peñafiel Brenda ${ }^{6}$, Coelho Rafael ${ }^{7}$, Eldesoky Ahmed Ramadan ${ }^{8}$, Ferrari Anezka ${ }^{9}$, Futo Ildiko ${ }^{10}$, Ghrieb Zineb ${ }^{11}$, Giovanardi Filippo ${ }^{12}$, Griguolo Gaia ${ }^{13}$, Khalo Lesiba ${ }^{14}$, Khokher Afsheen javaid ${ }^{15}$, Monteiro Vasconcelos Ines Isabel ${ }^{16}$, Patodiya Bharat ${ }^{17}$, Pereira Guimaraes Andre Luiz $^{18}$, Sharikadze Nino ${ }^{19}$, Siddig Shaimaa ${ }^{20}$, Soares Marlene ${ }^{21}$, Tecic Vuger Ana ${ }^{22}$, Villarreal Garza Cynthia ${ }^{23}$, Volovat Simona Ruxandra ${ }^{24}$, Zürrer-Härdi Ursina ${ }^{25}$, Bonollo Marta ${ }^{26}$ and Costa Alberto ${ }^{27}$

${ }^{1}$ Centro di Senologia della Svizzera Italiana (CSSI), Ente Ospedaliero Cantonale (EOC), Lugano, Switzerland

${ }^{2}$ Department of Radiation Oncology, King Hussain Cancer Center, Amman, Jordan

${ }^{3}$ Department of Oncology, Aga Khan University Hospital, Karatci, Pakistan

${ }^{4}$ Breast Cancer Department, Iaso Maternity Hospital, Athens, Greece

${ }^{5}$ Department of Medical Oncology, Hassan II University Hospital, Fes, Morocco

${ }^{6}$ Department of Radiation Oncology, Oncosalud, San Isidro, Peru

${ }^{7}$ Department of Clinical Oncology, Universidade Federal De Santa Maria, Santa Maria, Brazil

${ }^{8}$ Clinical Oncology and Nuclear Medicine Department, Mansoura University, Mansoura, Egypt

${ }^{9}$ Department of Oncology, Hospital Santa Paula, Sao Paulo, Brazil

${ }^{10}$ Department of Oncology, Bajcsy-Zsilinszky Kórház, Budapest, Hungary

${ }^{11}$ Harmandere Mahallesi, Emir Sultan Caddesi, 488 Erguvan Premium D56, Pendik, Istanbul, Turkey

${ }^{12}$ Department of Oncology, IRCCS Ausl Reggio Emilia, Guastalla, Italy

${ }^{13}$ Department of Surgery, Oncology and Gastroenterology, University of Padova, Padova, Italy

${ }^{14}$ Department of Oncology,Tshwane, 1 Military Hospital, South Africa

${ }^{15}$ Department of General Surgery, Liaquat National Hospital, Karachi, Pakistan

${ }^{16}$ Breast Unit, Berlin Breast Center Urban Clinic, Berlin, Germany

${ }^{17}$ Department of Medical Oncology, American Oncology Institute, Hyderabad, India

${ }^{18}$ Department of Medical Oncology, Hospital CLIOM, Maceio, Brazil

${ }^{19}$ Department of Clinical Oncology, Mardaleishvili Medical Centre, Tblisi, Georgia

${ }^{20}$ Department of Clinical Oncology, Khartoum Oncology Hospital/ RICK, Khartoum, Sudan

${ }^{21}$ Department of Radiation Oncology, De Muelenaere Oncology, Life Groenkloof Hospital, Pretoria, South Africa

${ }^{22}$ Trakoscanska 30, Sesvete, Zagreb, Croatia

${ }^{23}$ Breast Cancer Center, Hospital Zambrano Hellion, Tecnológico de Monterrey, San Pedro Garza Garcia, Mexico

${ }^{24}$ Department of Medical Oncology, Regional Oncology Institute, Iasi, Romania

${ }^{25}$ Department of Medical Oncology, Kantonsspital Winterthur, Winterthur, Switzerland

${ }^{26}$ Department of Obstetrics and Gynaecology, Ospedale Regionale di Lugano, Ente Ospedaliero Cantonale (EOC), Lugano, Switzerland

${ }^{27} \mathrm{ESO}-$ European School of Oncology, Milano, Italy

${ }^{\star}$ Correspondence to: Francesco (given) Meani (family), Department: CSSI - Centro di Senologia della Svizzera Italiana, Street name \& Number: via P. Capelli 1, City, State, Postal code, Country: Viganello, Ticino, 6942, Svizzera, Switzerland, E-mail: francesco.meani@eoc.ch

Received: August 04, 2020; Accepted: October 02, 2020; Published: October 07, 2020 


\begin{abstract}
BC management is a multifaceted and rapidly evolving field, requiring the acquisition of complex skills and knowledge that go well beyond those usually acquired during residency programs. An across the board training, covering at least part of domains from different but related specialties, must be acquired through dedicated multimodal and multidisciplinary curriculum $(\mathrm{CV})$. BC care can no longer rely on generic, single specialty training. Physicians who have developed a multidisciplinary, highly specialized, and structured $\mathrm{CV}$, with academic qualification, should profit from a preferential track for professional carrier advancement.

The European School of Oncology (ESO), in co-operation with Ulm University, has developed a structured course, named “Certificate of Competence in Breast Cancer (CCB)". Its aim is to provide BC specialists with multidisciplinary education and deliver an academic postgraduate title in the field.

The aim of this work is to investigate the degree of satisfaction of participants to the first two editions of the course and assess the yield, if any, in terms of professional gain, both on a personal and institutional level, derived from attending the multidisciplinary training of the CCB Program.
\end{abstract}

\section{Background and rationale}

There is a growing demand for academic education and standardized training among breast cancer (BC) specialists to increase their clinical (theoretical and practical) competence in multidisciplinary management of BC patients. Evidence has shown that multidisciplinary specialized approaches improve patient outcomes [1]; consequently, in the last few decades we have witnessed a progressive shift form a surgically-centered BC management to a multimodal, individualized treatment tailored on patient and cancer characteristics.

According to the 2006 European Parliament resolution, BC diagnosis and treatment should be organized in Certified Multidisciplinary Breast Units, equipped with highly specialized, adequately trained and dedicated professionals, who have undergone $\mathrm{BC}$ specialist training beyond that of their own specialty, encompassing all various aspects of $\mathrm{BC}$ management. The resolution demands member states to ensure nationwide provision of specialist breast units in accordance with EU guidelines, since treatment in a specialist breast unit has been proven to raise chances of survival and to improve quality of life. In other words, patients should not have to travel to access the highest quality of care. Every woman in Europe should have access to the same first-class early detection, diagnosis, treatment, and aftercare, irrespective of where she lives and her social status. Accordingly, professionals working in certified breast units must be adequately trained [2].

EUSOMA, the European Society of Mastology, starting from year 2000 , published a series of position papers defining the requirements of specialist breast units and guidelines on the standard training for health professionals dealing with BC [3]. Unlike in the USA, where specialist $\mathrm{BC}$ training is offered through national fellowship programs, that deliver multidisciplinary knowledge with rotations in different fields of BC management, in Europe there is still great variability and lack of standardization across countries. Despite the wide consensus on the need to develop quality standards, specialist training is still a matter of individual initiative and $[4,5]$, heterogeneous training systems across countries. The gap between the optimal recommended BC care/ training and actual practice is even bigger in low-middle-income countries where resource limitations greatly affect the provision of quality-controlled services [6].

BC management is a multifaceted and rapidly evolving field, requiring the acquisition of complex skills and knowledge that go well beyond those usually acquired during residency programs. An across the board training, covering at least part of domains from different but related specialties, must be acquired through dedicated multimodal and multidisciplinary curriculum (CV). BC care can no longer rely on generic, single specialty training.
With these premises, the European School of Oncology (ESO), in co-operation with Ulm University, has developed a structured course, named "Certificate of Competence in Breast Cancer (CCB)", with the contribution of internationally recognized physicians and scientists in the BC field. The Curriculum, focusing on both clinical and scientific competences, was established according to several practice and consensus guidelines (European Society for Medical Oncology-ESMO, the San Gallen Breast Cancer Conference, Advanced Breast Cancer ESO-ESMO International Consensus Conference-ABC, ESO-ESMO Breast Cancer in Young Women Consensus Conference-BCY) [7-10]. The CCB provides BC specialists with multidisciplinary education and delivers an academic postgraduate title $[5,11]$.

The course has now reached its third edition. Forty-two specialists were admitted to the first two editions of the program, completed the course and have satisfactorily passed the final examination at ULM University, obtaining an academic certificate of advanced studies (CAS). Twenty-five health professionals are currently participating in the third round (2019-2020).

\section{CCB Course description and target}

The academic Certificate of Competence in Breast Cancer Programme provides a total extent of 381 hours comprehensive learning, accordingly reported with a workload of 13 European Credit Transfer and Accumulation System Points (ECTS) by Ulm University. The Programme includes five on-line modules and three substantive attendance seminars with an overall duration of 13 months (Table 1). The CCB syllabus and examination, meet all the requirements to be part of the knowledge curriculum of the BRESO- Breast Surgical Oncology project [12]: in 2018 some of the major European societies involved in $\mathrm{BC}$ surgical training, research, education and advocacy came together creating this project with the specific aim to enhance and harmonize breast surgery training across Europe. Acknowledging the current very variable levels of training. BRESO proposes that all practicing breast surgeons in Europe should be certified in breast surgery by means of a high-level multidisciplinary training. The CCB curriculum, with its academic endorsement, fits well into such framework and is therefore potentially of great interest both to experienced professionals already involved in BC management, and young doctors in training, seeking multidisciplinary education to improve their $\mathrm{CV}$ and breast cancer patients' care at their home institution.

\section{Aim of the work}

According to what stated before, physicians who have developed a multidisciplinary, highly specialized, and structured CV, with academic qualification, should profit from a preferential track for professional carrier advancement. 
Francesco M (2020) Is multidisciplinary learning valuable to build a breast cancer specialist career? The perspective of the first 2 cohorts of the ESO-ULM Certificate of Competence in Breast Cancer (CCB)

Table 1. CCB3 curriculum

\begin{tabular}{|c|c|c|c|c|c|c|c|c|c|}
\hline & Attendance 1 & Module 1 & Module 2 & Module 3 & Attendance 2 & Module 4 & Module 5 & Attendance 3 & Total \\
\hline Timeline & spring & $\begin{array}{l}\text { May-july } \\
3 \text { monts }\end{array}$ & $\begin{array}{l}\text { Aug-sept } \\
2 \text { months }\end{array}$ & $\begin{array}{l}\text { Oct-nov } \\
2 \text { months }\end{array}$ & nov & $\begin{array}{l}\text { Gen- Mid march } \\
3 \text { months }\end{array}$ & $\begin{array}{l}\text { Mid March-Jun } \\
2.5 \text { months }\end{array}$ & June & 13 months \\
\hline Content & $\begin{array}{c}\mathrm{CCB} \\
\text { introduction }\end{array}$ & $\begin{array}{c}\text { Epidemiology } \\
\text { and Prevention, } \\
\text { biology and } \\
\text { clinical trials }\end{array}$ & $\begin{array}{l}\text { Principles of } \\
\text { diagnostics, } \\
\text { DCIS, gene } \\
\text { predisposition }\end{array}$ & $\begin{array}{l}\text { The breast Unit } \\
\text { model and LABC }\end{array}$ & $\begin{array}{l}\text { ABC Conference } \\
\text { Lisbon }\end{array}$ & $\begin{array}{l}\text { Management } \\
\text { of early breast } \\
\text { cancer }\end{array}$ & $\begin{array}{c}\text { Management } \\
\text { of advanced } \\
\text { BC, male BC, } \\
\text { supportive } \\
\text { therapies }\end{array}$ & $\begin{array}{c}\text { CCB stand- } \\
\text { alone seminar } \\
\text { including } \\
\text { practical training } \\
\text { + exam } \\
\text { Ulm University, } \\
\text { Germay }\end{array}$ & \\
\hline Workload & $\begin{array}{l}25 \mathrm{hrs} \\
\text { In-person }\end{array}$ & $\begin{array}{c}25 \text { units } \\
75 \text { hrs Distance } \\
\text { learning }+ \\
\text { module test }\end{array}$ & $\begin{array}{l}14 \text { units } \\
42 \text { hrs Distance } \\
\text { learning }+ \\
\text { module test }\end{array}$ & $\begin{array}{c}13 \text { units } \\
39 \text { hrs Distance } \\
\text { learning }+ \\
\text { module test }\end{array}$ & $\begin{array}{l}25 \mathrm{hrs} \\
\text { In-person }\end{array}$ & $\begin{array}{c}25 \text { units } \\
75 \text { hrs Distance } \\
\text { learning }+ \\
\text { module test }\end{array}$ & $\begin{array}{c}25 \text { units } \\
75 \text { hrs Distance } \\
\text { learning }+ \\
\text { module test }\end{array}$ & $\begin{array}{c}25 \mathrm{hrs} \\
\text { In-person } \\
+ \\
\text { Certificate exam }\end{array}$ & $\begin{array}{c}75 \mathrm{hrs} \text { in-person } \\
+ \\
306 \text { hrs Distance } \\
\text { Learning } \\
381 \mathrm{hrs} \text { total }\end{array}$ \\
\hline Credits & 1 ECTS & & $\begin{array}{c}52 \text { Units }-156 \mathrm{hrs} \\
5 \text { ECTS }\end{array}$ & & 1 ECTS & \multicolumn{2}{|c|}{$\begin{array}{c}50 \text { Units }-150 \mathrm{hrs} \\
5 \text { ECTS }\end{array}$} & 1 ECTS & 13 ECTS \\
\hline
\end{tabular}

LABC: locally advanced breast cancer; BC: breast cancer; hrs: hours

As part of the program CV, CCB attendees are warmly encouraged to endeavor in a peer reviewed publication, focused on the topic of professional training. In 2018, the participants to the second edition of the CCB published a manuscript on specific needs of BC trainees in Europe [5].

With this work, the fellows of the third cohort intended to investigate the degree of satisfaction of previous participants and the yield, if any, in terms of professional gain, both on a personal and institutional level, derived from attending the multidisciplinary training of the $\mathrm{CCB}$ Program.

\section{Materials and methods}

A specific questionnaire was developed by a group of experts including a senior Breast Surgeon, a senior Oncologist, one young Gynecologist involved in post-graduate training in BC surgery, one professor from the Faculty of Communication at USI (Università della Svizzera Italiana) and one administrative coordinator of post graduate oncology training programs from ESO.

A draft questionnaire was then piloted on a larger group of breast surgeons, oncologists, trainees, and administrative personnel to ensure content validity and usability; minor modifications were made based on feedbacks. The resulting questionnaire had 22 questions exploring 4 main domains:

1. Participants' background information (demographics, field of specialty, level of training/clinical experience, reasons for enrolling)

2. Administrative aspects of the CCB Program and application

3. CCB Program syllabus and design

4. CCB Program outcome and professional impact

The final version of the survey was reviewed and approved by all members of the task force and then published online, using the GOOGLE Forms platform.

All 42 participants from the first two cohorts of the CCB Program were invited to participate by an e-mail sent out from the central ESO office, which contained a link to the questionnaire.

The survey was available online for 8 weeks, and two email reminders were sent out during this period. The full questionnaire is available on Appendix A.
After the survey was closed, spreadsheet data were exported for analysis. Responses to the questions were extracted and summarized.

\section{Results}

\section{Participants' background information}

Demographics: The survey cohort was composed of 42 physicians, from 4 continents and 27 countries, the most represented were Brazil ( 4 , 9.5\%), Italy (3, 7.1\%) and South Africa (3, 7.1\%). All invited professionals (100\%) answered the survey. A slightly different distribution, from country of origin, is found as long as country of employment is concerned: 4 Brazil, 3 Italy, 3 Switzerland and interestingly enough 2 representatives from each of these 3 low-middle income countries: Egypt, Georgia and Pakistan (total 6, 14.2\%).

Mean age of the participants was 40.8 years; 27 (64\%) were female and $15(36 \%)$ were male. Considering the field of specialty: 29 were medical oncologists, 7 gynecologists, 5 radiation oncologists, and 1 general surgeon. Eighteen (42.9\%) worked in a university hospital, 15 $(35.7 \%)$ in a non-teaching public hospital and the remaining $9(21 \%)$ worked in the private sector.

The level of training/professional position at time of enrollment varied significantly, spanning from post-doc/ $\mathrm{PhD}$ students $(3,7.1 \%)$ to a stunning 8 chiefs of department (19.0\%) and 3 Professors (7.1\%); consultants were the largest group $(17,40.4 \%)$, the remaining being residents and fellows $(11,26.2 \%)$.

Reasons for enrolling: When asked about the main reason for applying to the CCB Program (more than one answer was allowed) the vast majority of the participants agreed on two aspects: 1) the need for up-to-date comprehensive knowledge in the field of $\mathrm{BC}$, 2) the search for a specific model of training, focusing on multidisciplinary management in modern oncology.

Other reasons included the opportunity to develop new international collaborations for clinical and research projects (networking and learning about $\mathrm{BC}$ treatment in other countries) and, not least, the wish to strengthen one's $\mathrm{CV}$ to boost a career advancement.

\section{Administrative aspects of the CCB Program}

This section of the survey aimed to explore participant's opinion on administrative aspects of the CCB program. Overall, a high degree of satisfaction has been recorded. More than $90 \%$ of participants agreed 
that website information (www.ESO.net) was informative and precise, while the application procedure was clear, easy to follow and reasonably structured in terms of time allocation.

Over $95 \%$ of responders believe that selection criteria for admission, based on personal CV and specific experience in the field were correct, while, on the other hand, about $20 \%$ considered that decisions criteria for final exclusion/inclusion were not fully transparent.

Thirty percent $(n=13)$ of responders thought the application fee was somehow too expensive. Interestingly, despite the majority was either from low-middle income countries (according to the Organization for Economic Co-operation and Development-OECD) and/or did not have a permanently paid professional position (students or residents), three outliers had stable professional positions in high income countries.

\section{Program design and syllabus}

The vast majority of the surveyed professionals agreed that the curriculum is well balanced, covering all aspects of multidisciplinary management of BC (88\%), in a very updated and detailed manner (95\%).

Two aspects the participants would like to be improved are the opportunities for networking (30\%) and the implementation of collaborative research projects among participants and possibly among home institutions (43\%).

When specifically asked for suggestions to improve the Program structure (more than one answers were allowed), five aspects were endorsed:

\section{To include periods of structured observership (71\%)}

2. To increase training sessions on multidisciplinary discussions during seminars (64\%)

3. To increase the time spent in the hospital during seminar 3 in Ulm (57\%)

4. To increase the focus on loco-regional treatments (40.5\%)

5. To increase the opportunities of clinical research training (35\%)

When looking specifically on the possibility to increase the knowledge on surgical and loco-regional treatments, the cohort felt divided. The responses have been very variable: $64 \%$ were definitely in favor, $12 \%$ undecided, $24 \%$ against. It is interesting to notice that 20 medical oncologists and 2 radiation oncologists were in favor, underpinning the concept that one aim of $\mathrm{BC}$ professionals is to widen the horizons of their knowledge, in line with the ultimate goal to improve multidisciplinary skills.

\section{Program outcome and professional yield}

Personal and institutional yield: When investigating professional benefits: $64 \%$ of responders declared to have implemented a significant change of $\mathrm{BC}$ management in their clinical practice because of what they have learnt through the CCB Program.

Significant update and innovations in internal protocols and guidelines are described together with implementation or improved efficacy of MDMs: in particular, they have developed better awareness and active participation in decision making processes during the multidisciplinary meetings (MDMs). Some report to having improved team working skills and gained capacity to better organize teaching sessions for students and ellows is also a goal worth to mention.
One responder stated to have set up a brand new department dedicated to $\mathrm{BC}$ care, using the experience gained from the course and from his/her international colleagues.

Networking (personal or formal agreement with other institutions): Opportunities for networking and experience sharing are well among the objectives of an international program of postgraduate advanced studies.

This domain was investigated through two specific questions about the activation of collaborative scientific projects among individuals or institutions.

On an individual level, one third $(33 \%, \mathrm{n}=14)$ of the participants were able to activate a collaboration with other colleagues which yielded two peer reviewed publications, several new research ideas, and international connections for networking and mentoring opportunities. On the other hand, $66 \%$ of the CCB fellows thought they had not achieved a significant networking advantage from attending the Program, at least at the time of the survey.

When looking at the Institutional level, 5 participants (12\%) responded they had the opportunity for visiting other BC Units in foreign countries, for example through the ESO fellowship program. One responder was able to get his home Institution on board a multicentric international research project with Breast Units from London and Paris.

Concrete outputs: Seventeen responders (40.5\%) took part to a publication on a peer reviewed international journal, $2(4.8 \%)$ coauthored a book chapter, 3 students (16.7\%) took advantage of the CCB to develop their doctoral thesis and 7 (16.7\%) stated to have arranged an exchange plan for themselves or other students. One participant, originally from a low-middle income country, but employed in the USA, was invited to participate in the panel of experts to review the ASCO 2019 Meeting Educational Book, together with several renown international BC experts.

On the other hand, 3 responders (31\%) said they had not gained any specific professional output from the CCB other than general multidisciplinary knowledge update.

Professional gain/advancement: The main professional gain acquired from the Certificate was related to multidisciplinary management of BC: $95 \%$ of responders declared that they felt

Finally, the survey scouted on specific changes in professional position that, directly or indirectly, ensued from attending the Certificate: 7 participants (16.7\%) reported a promotion as a consequence of the refinement of personal $\mathrm{CV}$ in terms of specialized training; 4 responders (9.5\%), decided to change working institution; $12(28.6 \%)$ declared to have implemented a new better organized and updated educational program at their home institutions.

The majority $(64 \%, n=27)$ of the attendees, used the CCB as a springboard to take part to other educational activities, preceptorships or formally organized Breast Cancer Fellowship programs abroad, organized by ESO, ESMO (European Society for Medical Oncology) or other international Societies (SSO - Society of Surgical Oncology, ASTRO-American Society of Radiation Oncology, and others).

What to keep and what to improve after CCB3: The last two questions of the survey pertained to what the participants liked and disliked the most. 


\section{Discussion and conclusions}

We are convinced the quality of medical care and expertise is linked to the quality of training provided to medical professionals.

The management of $\mathrm{BC}$ is paradigmatic as a multimodal and personalized care. It requires a vast knowledge over a complex array of multidisciplinary treatment strategies that only a dedicated team of professional can provide. Acquisition of this complex skill set requires dedicated training that goes beyond that of each specialty involved and leads to an overlap of knowledge from different disciplines.

As a matter of fact, currently no standardized training in $\mathrm{BC}$ treatment, whether for surgical or medical disciplines, exists across Europe. Consequently, among professionals dedicated to BC care and young doctors, there is shared desire for multidisciplinary training: the fact that 20 out of 29 medical oncologists in our cohort were in favor of increasing the share of lectures and practical training sessions, dedicated to loco-regional treatments within the CCB curriculum, is clearly in line with this.

On the surgical side, some of the major European societies involved in BC surgical training, research, education and advocacy came together this year to build the BRESO (Breast Surgical Oncology) Project: a widely endorsed attempt to enhance and harmonize breast surgery training across Europe by means of a structured, high-level, multidisciplinary training and certification [12].

The ESO-Ulm Certificate of Competence in BC is one of the official courses recognized by the BRESO certification and one of very few academic programs specifically designed to meet the needs of young professionals dealing with BC. Needs that are ultimately shared by the patients themselves, who are clamoring to benefit from a more highquality BC treatment.

The CCB represents a great opportunity to widen one's cultural background and refine the professional $\mathrm{CV}$ in the field. It is appropriate for professionals coming from all specialties involved in $\mathrm{BC}$ management, at any level of professional experience, from fellows to chiefs of department. It can deliver the tools for achieving one's goals, whether they are an advancement in professional hierarchy or the organization of a group of professionals in a specialized breast unit according to international certifications quality criteria.

This survey, designed by the participants of the third CCB cohort, offers the opportunity to quantify these aspects and collect a precious feedback for further improvements.

With this work, the fellows of the CCB $3^{\text {rd }}$ cohort investigated the degree of satisfaction of previous participants and, most importantly, the yield in terms of professional gain, both on a personal and institutional level, derived from attending the multidisciplinary training of the CCB Program. This information can help, both professionals already involved in patients care and young doctors in training seeking additional multidisciplinary knowledge, to navigate through the offer of postgraduate education and making a better-informed choice to build their career as BC specialist.

\section{Funding}

This research did not receive any specific grant from funding agencies in the public, commercial, or not-for-profit sectors.

\section{Acknowledgments}

We would like to acknowledge the attendees of the first two editions of the CCB for giving a fundamental contribution to this work responding to the questionnaire.
We would like to thank Prof. Lorenzo Cantoni, Full Professor - Faculty of Communication, Culture and Society-Università della Svizzera Italiana for the precious suggestions offered during the ideation and preparation phase of this survey.

We are also grateful to Professor Olivia Pagani for her constant support and wise supervision during the whole process.

We also thank all ESO Staff members for their collaboration and, in particular, Mrs Alexandra Zampetti for her organizational contribution and her efforts to make this survey successful.

Finally Mrs Samuel Righetti whose technical work was crucial for the ICT aspects. Finally yet importantly we would like to thanks the organizers of the $\mathrm{CCB}$ for their excellent work organizing the program of the Certificate.

\section{Conflict of interest statement}

The authors declare no potential conflicts of interest.

Alberto Costa, MD, is Chief Executive Officer of the European School of Oncology

\section{Ethical approval}

This work did not require ethical approval.

\section{References}

1. Kesson EM, Allardice GM, George WD, Burns HJG, Morrison DS (2004) Effects of multidisciplinary team working on breast cancer survival: retrospective, comparative, interventional cohort study of 13722 women. BMJ 344: e2718. [Crossref]

2. Meani F, Kovacs T, Spanic T, Costa A (2020) Breast cancer treatment in the modern era of multidisciplinary oncology: Now we need new models of training. Eur J Surg Oncol 46: 1393-1395. [Crossref]

3. Wilson ARM, Marotti L, Bianchi S, Biganzoli L, Claassen S (2013) The requirements of a specialist breast centre. Eur J Cancer 49: 3579-3587. [Crossref]

4. Rubio IT, Wyld L, Esgueva A, Kovacs T, Cardoso MJ, et al. (2019) Variability in breast cancer surgery training across Europe: An ESSO-EUSOMA international survey. Eur $J$ Surg Oncol 45: 567-572. [Crossref]

5. Montagna G, Anderson D, Bochenek-Cibor J, Bozovic-Spasojevic I, Campos C, et al (2019) How to become a breast cancer specialist in 2018: the point of view of the second cohort of the Certificate of Competence in Breast Cancer (CCB2). Breast 43: 18-21. [Crossref]

6. Wang C, Li X, Su S, Wang X, Li J, et al. (2019) Factors analysis on the use of key quality indicators for narrowing the gap of quality of care of breast cancer. BMC Cancer 19: 1099.

7. European Society for Medical Oncology: ESMO Clinical Practice Guidelines on Breast Cancer. https://www.esmo.org/guidelines/breast-cancer [accessed April 2020]

8. Burstein HJ, Curigliano G, Loibl S, Dubsky P, Gnant M, et al. (2019) Estimating the benefits of therapy for early-stage breast cancer: the St. Gallen International Consensus Guidelines for the primary therapy of early breast cancer 2019. Ann Oncol 30: 1541-1557. [Crossref]

9. Cardoso F, Senkus E, Costa A, Papadopoulos E, Aapro M, et al. (2018) 4th ESO-ESMO International Consensus Guidelines for Advanced Breast Cancer (ABC 4)†. Ann Oncol 29: 1634-1657. [Crossref]

10. Paluch-Shimon S, Cardoso F, Partridge AH, Abulkhair O, Azim HA Jr, et al. (2020) ESOESMO 4th International consensus guidelines for breast cancer in young women (BCY4). Ann Oncol S0923-7534 (20) 36363-36368.

11. Montagna G, Morgan J, Wandschneider W, Vinci A, Esgueva A, et al. (2020) Implementation of the BRESO theoretical and Practical knowledge Curriculum: The time has come. Eur J Surg Oncol 46(4 Pt B): 715-716. [Crossref]

12. Kovacs T, Rubio IT, Markopoulos C, Audisio RA, Knox S, et al. (2020) Theoretical and practical knowledge curriculum for European Breast Surgeons. Eur J Surg Oncol 46(4 Pt B): 717-736. [Crossref]

Copyright: (C2020 Francesco M. This is an open-access article distributed under the terms of the Creative Commons Attribution License, which permits unrestricted use, distribution, and reproduction in any medium, provided the original author and source are credited. 